\title{
Using BEopt (EnergyPlus) with energy audits and surveys to predict actual residential energy usage
}

\author{
Joshua D. Rhodes ${ }^{\mathrm{a}, *}$, William H. Gorman ${ }^{\mathrm{b}}$, Charles R. Upshaw ${ }^{\mathrm{c}}$, Michael E. \\ Webber ${ }^{\mathrm{c}, \mathrm{d}, * *}$ \\ ${ }^{a}$ Department of Civil, Architectural and Environmental Engineering, The University of \\ Texas at Austin, 301 E Dean Keeton St. Stop C1752, Austin, TX 78712-1094 \\ ${ }^{b}$ Department of Chemical Engineering, The University of Texas at Austin, 200 E. Dean \\ Keeton St. Stop C0400, Austin, Texas 78712-1591 \\ ${ }^{c}$ Department of Mechanical Engineering, The University of Texas at Austin, 204 E. \\ Dean Keeton Street, Stop C2200, Austin, Texas 78712-1591 \\ ${ }^{d}$ Energy Institute - The University of Texas at Austin, 2304 Whitis Ave Stop C2400 \\ Austin TX 78712-1718
}

\begin{abstract}
Simulations of building energy use can give insights into how energy efficiency retrofits and operational changes can influence a building's total and temporal energy use. However, before those models are used to generate recommendations, it is important to understand how accurately the simulations predict actual energy use. This paper seeks to determine model accuracy by considering 54 homes in Austin, TX that are part of a smart grid demonstration project. Data about the homes were collected with energy audits then converted into energy models using BEopt (version 2.0), a residential building-focused graphical user interface (GUI) front-end for EnergyPlus de-
\end{abstract}

\footnotetext{
${ }^{*}$ Corresponding author

***Principal corresponding author

Email addresses: joshdr@utexas.edu (Joshua D. Rhodes), will.gorman5@gmail.com (William H. Gorman), crupshaw@utexas.edu (Charles R. Upshaw), webber@mail.utexas.edu (Michael E. Webber)
} 
veloped by NREL. Actual meter reads (kWh) were compared to simulation results for four cases: 1) energy model output with typical meteorological year (TMY) weather data, 2) output with an actual meteorological year weather (AMY) file created using real weather data from a year during which actual energy use measurements were made, 3) model output with thermostat user behavior data, and 4) output using a simplified home geometry. The purpose of this analysis was to evaluate how well this model, as it is, could be expected to predict energy usage using varying levels of inputs that might be included on an energy audit and survey. Results indicate that the modeling software was able to estimate aggregate annual electrical energy usage within $1 \%$ (for groups of homes) but might vary up to $28 \%$ (absolute) for an individual home. Using AMY weather data (Case 2) yielded results within $2.4 \%$ of measured (aggregate) energy use, while using a TMY3 weather file for Austin yielded results within $9 \%$ of (aggregate) actual usage. Using a simplified home geometry did not appreciably change the results of the model or its ability to simulate real usage. Results show that while the model does a reasonable job predicting usage for homes with average usage, the model has trouble predicting usage of homes with low or high consumption, particularly homes below $5 \mathrm{kWh} / \mathrm{ft}^{2} /$ year $\left(0.47 \mathrm{kWh} / \mathrm{m}^{2} /\right.$ year $)$ of average energy use or above $10 \mathrm{kWh} / \mathrm{ft}^{2} /$ year $\left(0.93 \mathrm{kWh} / \mathrm{m}^{2} /\right.$ year $)$, likely due to unknowns about the home when BEopt defaults were used.

Keywords: residential buildings, energy audits, measured electricity data, energy models 


\section{Introduction}

In the United States, buildings are responsible for 40.36 Quads $(40.36 \times$ $10^{15} \mathrm{BTU}$ ), or about $40 \%$ of total primary energy consumption per year, 22.15

Quads or about $22 \%$ of which are used in residential buildings [1]. Also, the United States residential sector is responsible for about $20 \%$ of United States carbon emissions or about $4 \%$ of the world's total [2]. While there are over 130 million residential units in the United States, only $0.1 \%$ of all R\&D is spent in the residential sector [3]. This lack or R\&D means the residential sector represents an underinvested opportunity for energy savings.

Residential structures are unique in form, build, and use. Even tract homes built by the same builder in the same time period can be similar in outward appearance, but vary greatly in terms of efficiency and energy use. Residential air-conditioning systems are particularly disruptive to the electric grid and create significant swings in demand. In Texas, 7.7 million households (both single-family and multi-family units) use approximately $43 \mathrm{TWh}$ of electricity for air-conditioning annually [4] - about $13 \%$ of total electricity use in Texas. The percentage of electrical load on the Electric Reliability Council of Texas (ERCOT) electric grid attributed to residential users increases from about $20 \%$ in the spring to $48 \%$ in the summer of 2010 (400\% real increase, 6,139 vs. 30,735 MW in 2010), mostly due to the operation of residential air-conditioning systems [5]. So much heat is removed from buildings by air-conditioners that it can have an impact on the local ambient air temperature in some places [6]. Furthermore climate change might increase building energy use in hot climate zones [7].

Numerous studies have evaluated the energy savings associated with in- 
creasing the energy efficiency of the United States residential building stock [822]. Many studies have focused on various aspects of residential buildings such as heating, ventilation, and air-conditioning (HVAC) equipment, façade, air tightness, insulation levels, duct leakage, and construction type. Evidence suggests that there is significant value in continuous energy commissioning (actually verifying that a building is performing to the prevailing energy code) and monitoring of buildings [23] and that significant numbers of residential buildings built to energy codes are non-compliant [24, 25]. Although many residential efficiency standards exist [26, 27], few studies [13] can estimate residential resource consumption and savings for a large, statistically significant portion of a local residential building stock because of a lack of data.

Many different building energy simulation models have been developed over the last 50 years to help users predict specific building performance characteristics [28]. Recently, residential energy use modeling has become popular to provide homeowners feedback about their homes' energy performance [29]. One platform for building energy simulation, EnergyPlus was developed by the US Department of Energy (DOE) and was released in 2001, with a focus on commercial buildings. Recently, a residential front-end to EnergyPlus, BEopt (version 2.0 is used in this analysis), was developed by the National Renewable Energy Laboratory (NREL) to provide easier and better modeling of residential homes [30]. However, modeling residential buildings can lead to systematic errors that need to be understood to evaluate the applicability of the model's results in the real world [29, 31-34]. Many studies of building energy modeling have small sample sizes [35, 36], focus on 
benchmarking methodologies [37, work to simplify current models [38], or do not focus on residential buildings. Also, human behavior affects residential energy use [39, 40], and thus more realistic building occupant schedules can lead to more realistic models [41]. Generally speaking, calibration helps the accuracy of models [42], but the information to perform calibration is seldom available.

Thus, it is valuable to assess the accuracy of modeling programs. This work seeks to assess the ability of EnergyPlus (via BEopt) to simulate residential energy use in a hot and humid climate by use of 1) a database of residential home energy audits, 2) data from a smart grid demonstration project, and 3) modeling. Understanding how these models predict actual energy usage in Austin's hot and humid climate under different design considerations can lead to better simulations and retrofit recommendations [43, 44].

\section{Datasets used in this analysis}

This analysis considers a group of 54 single-family homes with energy audits and metered electricity use data. These datasets were provided by Pecan Street Inc., a smart grid demonstration project that is based in Austin [45], and Austin Energy, the local electric utility. The Pecan Street smart grid demonstration project is administered by a 501(c)(3) non profit organization that has the stated goal to "re-imagine Austin's energy distribution system in a way that could support and accelerate the installation and management of smarter and cleaner electricity services" [46]. The project collects highfidelity sub circuit electricity data (1 second or better) from hundreds of homes in Austin, TX and has begun satellite programs in Colorado and Cal- 
ifornia. A smaller group of the homes also have water and natural gas data (2 gallon and 1 cubic foot measurements, respectfully) monitored a stored for research. The program also collects yearly surveys of the research participants and has a database of energy audits on most homes in the project. The audits are similar to a citywide program, The Energy Conservation Audit and Disclosure (ECAD) ordinance in Austin, which mandates that homes over 10 years old must have an energy audit before they can be sold [8, 9, 47]. However, the audits used in this analysis contain additional house information, such as areas and locations of windows and ACH50 values [45]. Table 1 summarizes the key audit data fields that were used to build the models.

In addition to the data on residential home characteristics, electricity use data were also retrieved from Pecan Street (hourly whole home electricity use data) and Austin Energy (daily whole home electricity consumption readings). Daily data were available for all homes, while hourly data were only available for a subset of the homes. Also, demographic data about the occupants were also available for this analysis from surveys administered by Pecan Street for each of the 54 single-family homes. In part of our analysis, we also compared the outputs of models that used Typical Meteorological Year (TMY) weather data along with real measured weather data for Austin in 2011, a particularly hot year for Austin. TMY data are weather data files that are curated by NREL and represent a year's worth of typical weather for a given location citeWilcox2008. The 2011 weather date were obtained through a commercial weather file source [48]. Austin's weather is characterized as 'humid subtropical with hot summers and mild winters' [49]. Table 2 below shows a summary of Austin's average weather [50]. 
Table 1: The following characteristics from the 54 homes were utilized for the energy simulations in this analysis, where BTU is a British Thermal Unit, COP is the coefficient of performance $\left(\mathrm{kW}_{\text {thermal }} / \mathrm{kW}_{\text {electric }}\right)$ of the air-conditioning systems, AFUE is the annual fuel utilization efficiency of the furnace (the percent of useful heating energy over total energy input), and ACH50 is the air changes per hour in a space when the pressure difference between the space and the ambient is $50 \mathrm{~Pa}$.

\begin{tabular}{lrrrr}
\hline Parameter & Unit & Mean & Standard Dev. & Median \\
\hline Year Built & - & 1965 & 18.3 & 1964 \\
Conditioned Area & $\mathrm{m}^{2}$ & 167.3 & 85.2 & 150.4 \\
House Volume & $\mathrm{m}^{3}$ & 430.8 & 253.5 & 367.7 \\
Window Area & $\mathrm{m}^{2}$ & 20.5 & 12.3 & 19.2 \\
Attic R Value & ${\mathrm{hr}-\mathrm{ft}^{2}-{ }^{\circ} \mathrm{F} / \mathrm{BTU}\left[\mathrm{m}^{2}-\mathrm{K} / \mathrm{W}\right]}^{2}$ & $23.2[4.1]$ & $10.9[1.9]$ & $23[4.0]$ \\
Duct Leakage & $\%$ & 14.8 & 9.7 & 12.6 \\
Duct R Value & ${\mathrm{hr}-\mathrm{ft}^{2}-{ }^{\circ} \mathrm{F} / \mathrm{BTU}\left[\mathrm{m}^{2}-\mathrm{K} / \mathrm{W}\right]}_{4.3}[1.9]$ & $1.9[0.6]$ & $4.0[1.8]$ \\
AC Capacity & $\mathrm{kW}$ & 10.8 & 3.4 & 10.5 \\
System Efficiency & $\mathrm{COP}$ & 3 & 2.3 & 2.9 \\
Furnace Capacity & $\mathrm{kW}$ & 19.6 & 6.3 & 19.9 \\
Furnace & $\mathrm{AFUE}$ & 80.3 & 1.7 & 80 \\
ACH50 & - & 11.7 & 5.2 & 10.8 \\
\hline
\end{tabular}


Table 2: Summary of Austin, TX monthly average temperatures $\left({ }^{\circ} \mathrm{C}\right)$.

\begin{tabular}{lrrr}
\hline Month & High & Low & Mean \\
\hline Jan & 17 & 5 & 11 \\
Feb & 18 & 7 & 13 \\
Mar & 22 & 11 & 17 \\
Apr & 27 & 15 & 21 \\
May & 31 & 19 & 25 \\
Jun & 33 & 22 & 28 \\
Jul & 36 & 23 & 29 \\
Aug & 36 & 24 & 30 \\
Sep & 33 & 21 & 27 \\
Oct & 28 & 16 & 22 \\
Nov & 22 & 11 & 17 \\
Dec & 17 & 6 & 12 \\
\hline
\end{tabular}




\section{Methods}

\subsection{Construction of the models.}

This analysis was conducted for 54 home energy models for 4 different scenarios (228 total model runs). The main performance criterion in this analysis was a comparison of the model's predicted yearly electricity use to measured utility and smart metered electricity use. The process for developing the 54 home models for the four scenarios is shown in Figure 1 . The home models were constructed using BEopt, a graphic user interface that provides functionality to build a residential home's geometry and indicate specific features of each individual home (e.g. home insulation values, duct leakage, AC efficiency, etc). The software can use either the DOE2/TRNSYS [51] or the EnergyPlus simulation engine, and for this analysis, we utilized the EnergyPlus engine because it includes more flexibility in simulations. Furthermore, the program contains three main interface screens to enter information used by the simulation engine to calculate a home's energy profile: the geometry screen, the options screen (insulation levels, window types, etc.), and the site screen (location, weather files, utility rate structures, etc.).

Information on the specific functionality for each screen can be found in prior literature [30]. The program default values were used in cases where the energy audit did not provide specific details of the building (e.g. wall insulation, miscellaneous electric load, floor insulation, refrigerator, cooking range, dishwasher, and lighting information). The variables that were updated due to availability of audit data were: building orientation; neighbor spacing; exterior finish; unfinished attic type and insulation; roof material; radiant barrier; window areas; window type; home air leakage; clothes dryer 


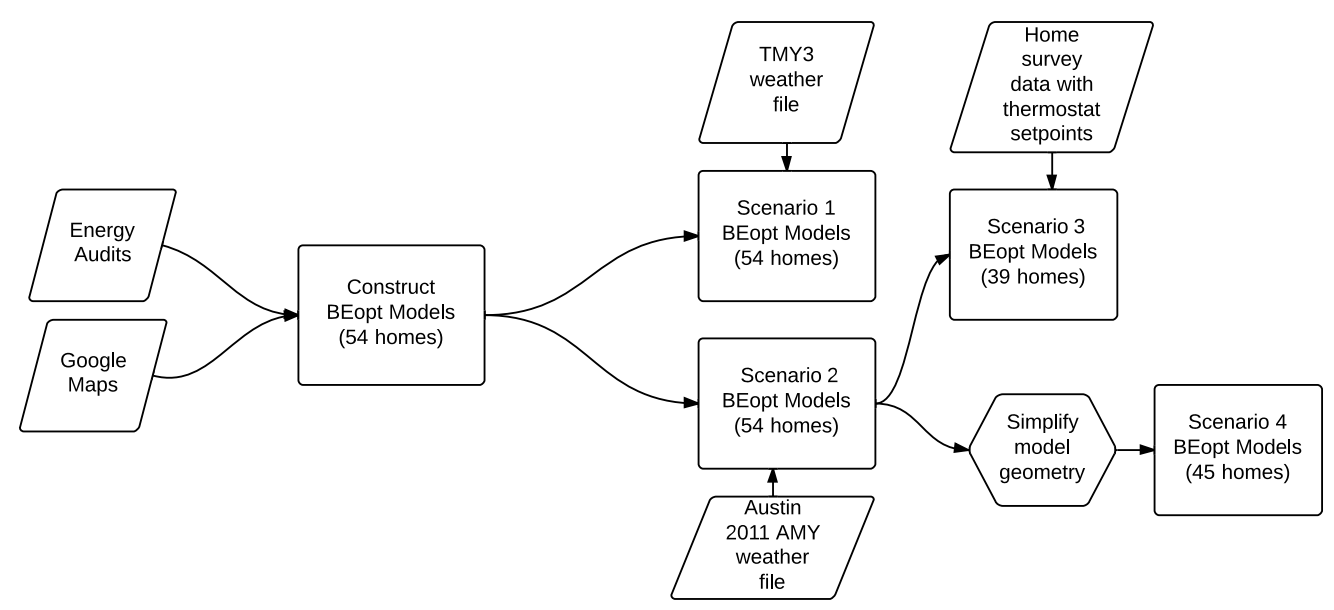

Figure 1: Flowchart for creating and analyzing the 54 residential homes using BEopt and EnergyPlus.

and water heater fuel; central AC and furnace type, efficiency, and size; duct insulation; and duct leakage.

\subsection{Scenarios considered for analysis}

In total, four different model scenarios (Figure 1) were developed to compare the 54 homes in different situations to monitor the effect of different parameters. The first scenario used TMY3 weather data and the second scenario used actual Austin 2011 weather data. Although comparing model output that used TMY3 weather input to actual use data could be considered an 'apples to oranges' comparison, it was included to show a progression of model outputs. No home properties were changed between these two scenarios. The third scenario included thermostat set-point information that was obtained from the homeowner surveys. This scenario was developed to observe the effect of thermostat behavior on the model's overall performance. 
The fourth scenario simplified the geometry of the homes to test the effect of geometry on the home electricity use. In total, nine generalized geometries existed (in the original home layouts) before modification for the 54 modeled homes. These geometries are shown in Figure 2. To determine the extent to which complicated geometries influence electricity consumption, each complex home geometry was simplified to geometry A while maintaining the other characteristics such as square footage, duct leakage, etc. For comparison purposes, special attention was given to ensure that the percent change of the new square footage to the square footage of the original model remained within $1 \%$.

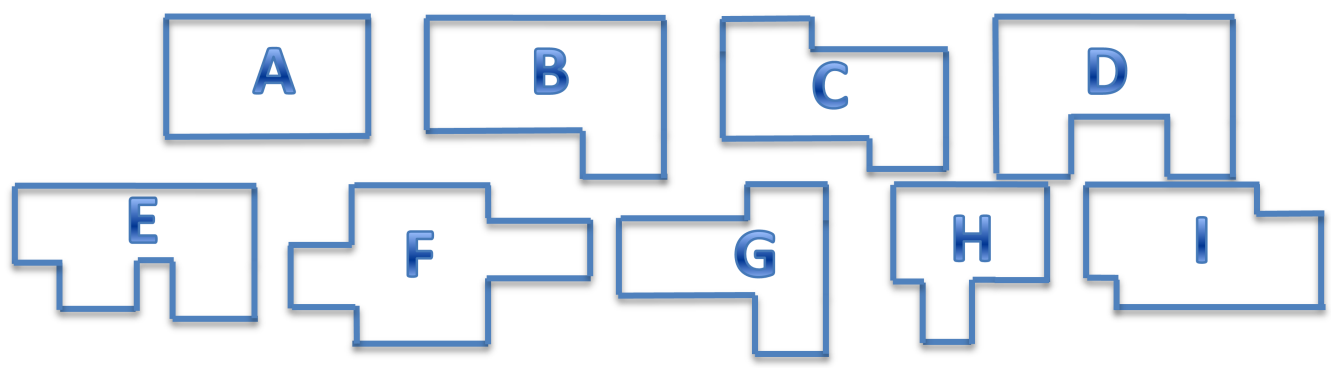

Figure 2: Nine floor geometries were used to estimate energy consumption of the 54 residential homes for scenarios 1-3. Scenario 4 used only geometry A while keeping other characteristics the same.

To observe the effect of the different scenarios, the model output was compared to actual electricity use data. First, electricity use measured by the local utility was compared to simulated electricity consumption from the model over an entire year. Error was calculated for each individual BEopt 
model by Equation 1:

$$
\text { Relative Error }=\frac{E_{B \text { Eopt }}-E_{U t i l i t y}}{E_{U t i l i t y}} \times 100
$$

where relative error is the percent difference between the BEopt-modeled and utility-measured consumption data, $E_{B E o p t}$ is the electricity consumption predicted by the BEopt model for one home $(\mathrm{kWh})$, and $E_{\text {Utility }}$ is the electricity consumption provided by Austin Energy, the local utility company $(\mathrm{kWh})$.

To assess the model's ability to predict electricity consumption in a community, (in this case, an aggregated relative error for the 54 homes) each model's electricity consumption in kWh over the entire year was summed and compared with the summation of each home's utility data in kWh over the entire year via Equation 2

$$
\text { Aggregated Relative Error }=\frac{\sum E_{\text {BEopt }}-\sum E_{U t i l i t y}}{\sum E_{U t i l i t y}} \times 100
$$

where Aggregated Percent Error is the error when the modeled consumption for all 54 homes' are summed and compared with the sum of the utility data for the 54 homes. Thus, Equation 2 is a measure of the performance of a group of homes as a whole.

The same methods were applied to monthly real and simulated values of energy use for a subset of the homes.

Finally, hourly temporal profiles produced by the BEopt model were compared with hourly electricity use data to determine whether certain time periods throughout the day or seasons throughout the year affected the performance of the BEopt model. These simulations were run with actual 2013 
weather data in order to compare output with the actual temporal home demand - the actual temporal home data were only available for 2013. To generate the temporal profiles in BEopt, modeled electricity demand data for August 30, 2013 were averaged for 5 homes. This average profile was compared to an average profile generated from the same homes' actual usage on August 30, 2013. The same procedure was followed to produce a winter temporal profile comparison using actual and simulated data for February $12,2013$.

\section{Results}

During the construction of the models, the pool of available homes for each scenario changed due to availability of data. Fifteen homes did not have thermostat set-point data, and therefore, only 39 homes of the available pool of 54 homes were modified with temperature set-point information for scenario 3. Furthermore, 12 of the 54 homes were initially modeled with a type A geometry, and therefore, only 42 homes of the available pool of 54 homes were analyzed for scenario 4 since they were the only homes for which simplified geometry was relevant.

\subsection{Yearly electricity usage comparison: modeled vs. measured}

Figure 3 presents the histograms of the 54 individual homes' relative error values for scenarios 1, 2 and 3. Scenario 4 was not included in this analysis since it was not being compared to measured electricity data but rather to its deviation from an original model due to a modification of geometry parameters. The average relative error (Equation 1) for the individual homes was $3.29 \%$ (s.d. $32.5 \%$ ), $18.3 \%$ (s.d. $36.5 \%$ ), and $16.0 \%$ (s.d. $31.8 \%$ ) for scenario 


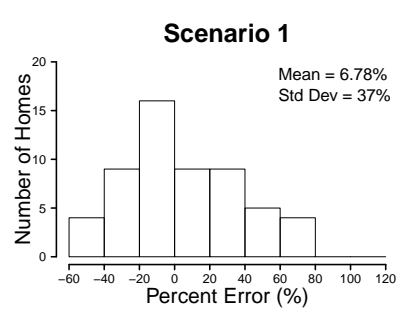

1,2 , and 3 respectively. While a decrease from scenario 2 to 3 is expected due to the improved data quality with temperature set-point information, the increase from scenario 1 to 2 was unexpected. We hypothesize that the BEopt model might over predict HVAC energy usage in the shoulder seasons (see Section 4.2). Thus, when the actual 2011 weather data were used for Austin, the model increased its over-prediction because 2011 was a much hotter year than the average TMY3 data. However, since we did not have sub circuit data from the measured homes, we are not able to test this hypothesis.
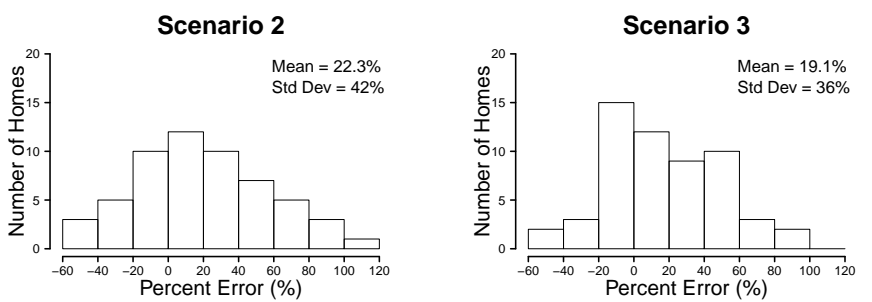

Figure 3: Histograms of relative errors for scenarios 1-3 of model construction showing changes in predictability of model with TMY3 weather data for Austin (Scenario 1), Austin 2011 weather data (Scenario 2), and Austin 2011 weather data including temperature setpoint data for 39 homes (Scenario 3) with one outlier (the same home) removed from each scenario for clarity.

To explore the hypothesis that the simulation model over predicts electricity consumption for certain homes, we looked at Energy Information Agency (EIA) data on residential homes' energy consumption normalized over square footage. The EIA data indicate that the average value is $8.1 \mathrm{kWh} / \mathrm{ft}^{2} /$ year $\left(0.75 \mathrm{kWh} / \mathrm{m}^{2} /\right.$ year $)$ for Texas [4]. However, a number of the homes modeled in this study exhibited smaller values for their site energy consumption per square foot with an average value of $6.99 \mathrm{kWh} / \mathrm{ft}^{2} /$ year $\left(0.65 \mathrm{kWh} / \mathrm{m}^{2} /\right.$ year $)$. This analysis might suggest either that some of the utility data may be miss- 
ing some values, the homes are more efficient than the average Texas home, or that the model has difficulty modeling homes that consume less energy on average per square foot. For example, 28 homes had average utility consumption values below $7 \mathrm{kWh} / \mathrm{ft}^{2} /$ year $\left(0.65 \mathrm{kWh} / \mathrm{m}^{2} /\right.$ year $)$, and when these homes are removed from the calculation, the relative error for each individual home drops significantly for scenarios 2 and 3 and increases for scenario 1 to $-16.2 \%$ (s.d. $22 \%$ ), $-3.7 \%$ (s.d. 24\%), and $-2.6 \%$ (s.d. $23 \%$ ) for scenarios 1, 2 , and 3 respectively. These results follow the expected progression from scenario 1-3 as data quality improved, and this analysis is graphically depicted in Figure 4

However, simple relative error calculations on individual homes might unjustifiably put more weight on the relative errors of smaller homes that consume less electricity compared to the aggregate electricity consumption of the 54 homes. Thus we consider the aggregated relative error for the 54 homes (Equation 2). This type of aggregated error is an appropriate tool to use for studies where modeled communities are used for analysis rather than individual homes [52]. For the 54 homes, the aggregate errors were $-10.93 \%, 2.70 \%$, and $2.41 \%$ for scenario 1,2 and 3 , respectively. As the input data quality increased from scenarios 1 to 3 so did the models' performance. These results are summarized in Table 3. Also given in Table 3 is a break down of the absolute relative error, for which the absolute value of each homes relative error was taken before the values were averaged in each scenario. Further improvements could most likely be made by more information about the behavioral patterns of homeowners. While model results for an individual home can have a wide range of significant absolute 


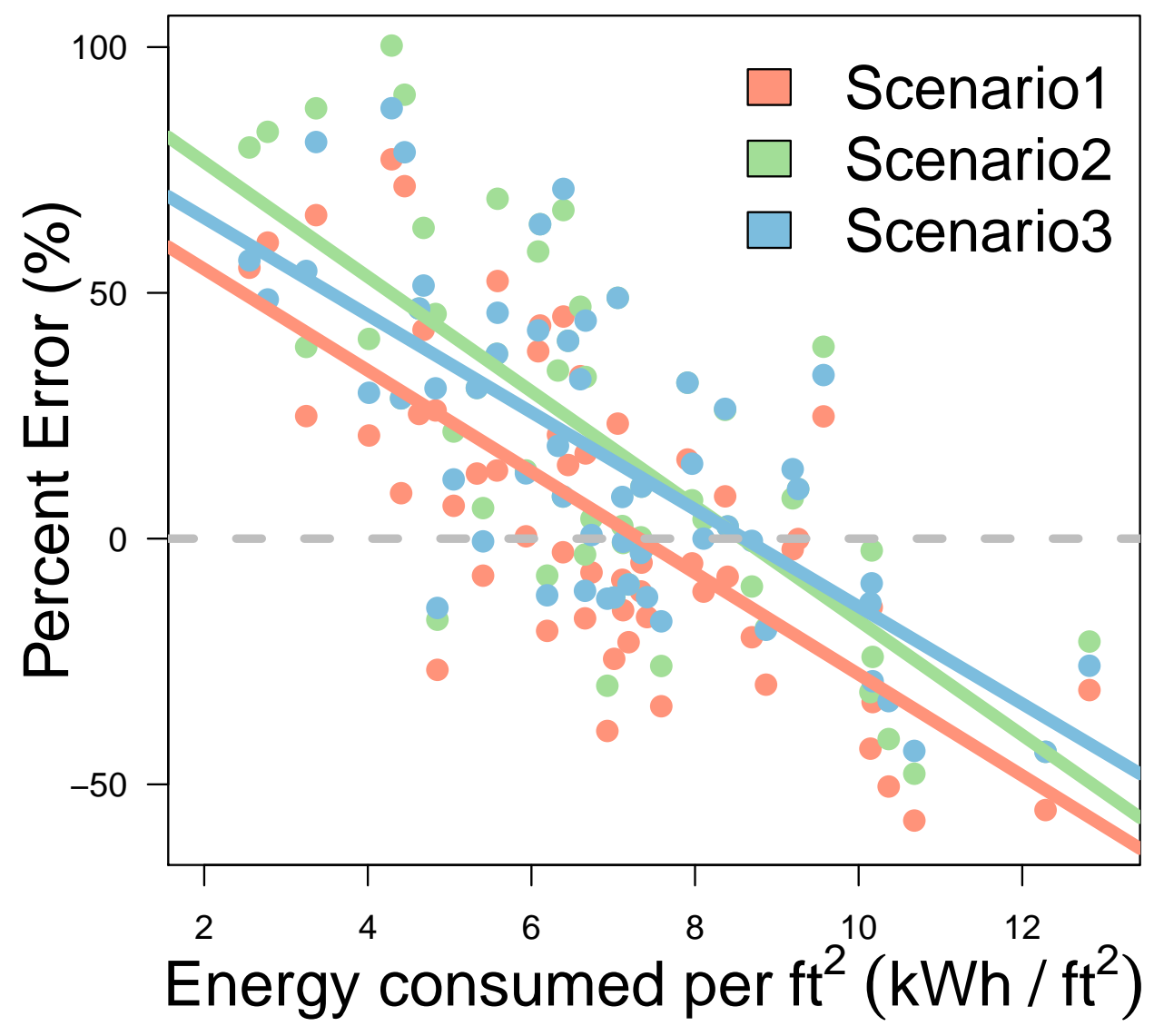

Figure 4: Graph comparing relative errors for scenarios 1-3 to their energy consumption per square foot showing that the BEopt models perform worse over certain bounds (below $5 \mathrm{kWh} / \mathrm{ft}^{2} /$ year $\left(0.46 \mathrm{kWh} / \mathrm{m}^{2} /\right.$ year $)$ and above $10 \mathrm{kWh} / \mathrm{ft}^{2} /$ year $\left(0.93 \mathrm{kWh} / \mathrm{m}^{2} /\right.$ year $\left.)\right)$ and that in general relative error has an inverse relationship with energy consumed per floor area. Thus it seems that the model is able to more accurately estimate the energy usage of homes that are closer to the average Texas home $\left(8.1 \mathrm{kWh} / \mathrm{ft}^{2} /\right.$ year, $0.75 \mathrm{kWh} / \mathrm{m}^{2} /$ year $)$, but the model is less accurate for homes that use significantly more or less energy. 
error values, when considered in aggregate, the model performed much better. The effect of the lack of behavioral data on BEopt model performance is best observed by analysis of the temporal consumption profiles in the next section.

Table 3: Summary of Results from Scenarios $1-4$

\begin{tabular}{lrrrr}
\hline Calculations & Scenario 1 & Scenario 2 & Scenario 3 & Scenario 4 \\
\hline Relative error (\%) & 3.29 & 18.33 & 16.03 & - \\
w/ homes > $5 \mathrm{kWh} / \mathrm{ft}^{2}\left(0.46 \mathrm{kWh} / \mathrm{m}^{2}\right)$ & -5.81 & 7.92 & 7.91 & - \\
w/ homes > $7 \mathrm{kWh} / \mathrm{ft}^{2}\left(0.65 \mathrm{kWh} / \mathrm{m}^{2}\right)$ & -16.17 & -3.69 & -2.60 & - \\
Absolute relative error $(\%)$ & 25.93 & 31.10 & 27.81 & 1.22 \\
w/ homes > 5 kWh $/ \mathrm{ft}^{2}\left(0.46 \mathrm{kWh} / \mathrm{m}^{2}\right)$ & 21.38 & 23.20 & 22.06 & - \\
w/ homes > $7 \mathrm{kWh} / \mathrm{ft}^{2}\left(0.65 \mathrm{kWh} / \mathrm{m}^{2}\right)$ & 21.79 & 18.45 & 18.11 & - \\
Aggregated relative error $(\%)$ & -10.93 & 2.70 & 2.41 & - \\
\hline
\end{tabular}

\subsection{Monthly electricity usage comparison: modeled vs. measured}

Homes from Scenario 3 (2011 weather data + temperature setback data, $\mathrm{n}=42$ ) were also compared for their monthly usage. Figure 5 shows both a bar chart monthly comparison of the average of all the homes (top) and a box plot distribution of the individual relative errors of the homes for each month.

The model was able to follow the general shape of the monthly use profile. However, there were some months, particularly those in the shoulder seasons, that were more off (greater average percent difference) than others. These greater differences can also be seen in the box plot distributions on the lower graph - note that the solid black lines in the individual boxes are median 


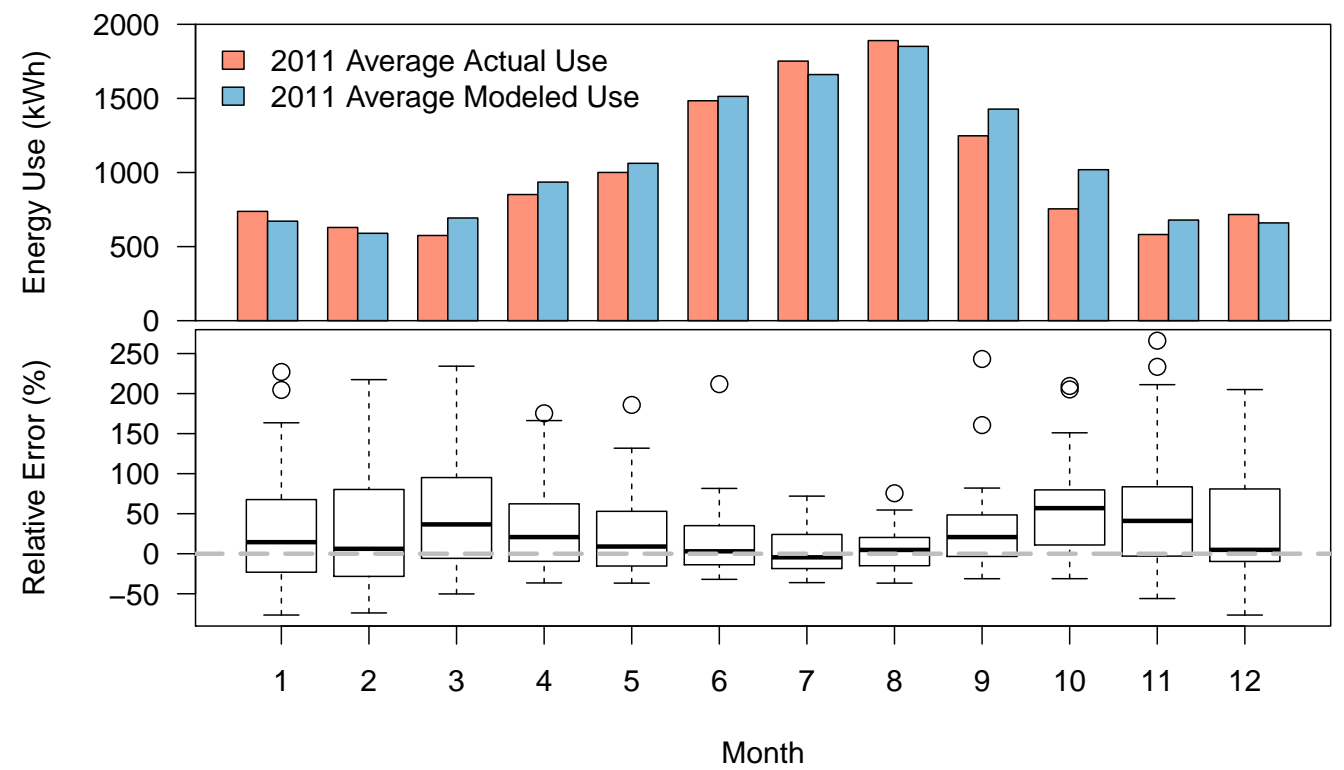

Figure 5: Double graph showing, on top, the 2011 average monthly energy usage of the 54 homes as compared to the 2011 average modeled monthly consumption of the same homes. The bottom portion of the graph shows a box plot distribution of the individual monthly relative errors (Equation 1) of each home for each month. The model is able to predict the general shape, but seems to be predicting high during the shoulder (spring and fall) seasons, which is shown in both figures. The dashed gray line in the lower figure represents a zero relative error and is included for ease of relative comparison between the months and the solid black line in each box plot is the median for that month. The homes in this section are from Scenario 3. 
values. The months of September and October have the greatest differences and could be due to some homes with rather high percent differences having changed their thermal comfort settings (stopped using their air conditioner) whereas the model still deemed it necessary. Also, the differences in the shoulder months could be from other thermostat behavior such as not heating homes on days with chilly mornings where the weather is expected to require cooling in the afternoon.

\subsection{Hourly electricity profile comparison: modeled vs. measured}

In this section, hourly consumption data were taken from the model hourly output file and compared with hourly data taken from a smart grid demonstration project in Austin, TX. There were only 5 homes that had audits and temporal energy usage, which limited this section of analysis to those 5 homes. These homes had an average build year of 1968, size of 152 $\mathrm{m}^{2}$, house volume of $388 \mathrm{~m}^{3}$, window area of $20.3 \mathrm{~m}^{2}$, attic insulation of R-20 (RSI-3.52), duct leakage of $11.8 \%$, duct R-value of 3.8 , air conditioner size of $10.7 \mathrm{~kW}$, air conditioner efficiency of COP 2.7, furnace capacity of19.7 $\mathrm{kW}$, furnace AFUE of 80, and an ACH50 value of 12.4. Figure 6 shows the differences between the metered data and the model generated daily consumption profile for the summer and winter seasons. In the summer month (Figure 6, bottom), this analysis shows that the model under predicted average electricity demand in the early morning and late afternoon for these five homes. Behavioral patterns, such as times of leaving/returning home, that were not reported by homeowners could be driving the homes' differing energy consumption compared to the model. Newer versions of BEopt $(2.2+)$ now include a specific schedule builder. It also could be the case that the 
model has trouble simulating home performance in a hot and humid climate such as that of Austin.

The winter graph (Figure 6, top) shows that the BEopt model did a fairly good job following the consumption profile for the 5 smart metered homes selected for analysis with the exception of a higher morning spike when people are typically starting their day. While it does appear that the model over predicts consumption between $9 \mathrm{AM}$ and $5 \mathrm{PM}$, the overall trends aligns reasonably well. Figure 7 shows a more detailed look at the hourly analysis by showing box plots of the actual and measured values side by side.

Figure 7 shows how assumptions built into the models can lead to similar use between homes (tighter blue box plots), while actual home use can be highly variable (larger red box plots). However, as Figure6 showed, as groups of homes are averaged, the results are better. In all, spikes and offsets are still present and suggest that BEopt will continue to have difficulty predicting temporal profiles due to the fact that behavior becomes such an important factor once the model is analyzed at the daily time scale. For this reason, this energy model, in its current form, ought to be used sparingly to predict exact daily electricity demand profiles for individual homes. However, seasonal average curves might be acceptable, but data limitations did not allow us to consider this, but could be the topic of future work.

\subsection{Geometry modification analysis.}

Scenario 4 involved the modification of home geometry of the scenario 2 models to determine whether home geometry characteristics were a major driver of simulated energy use. Overall, the analysis showed that a simplified geometry does not change model performance significantly. In total, 32 home 


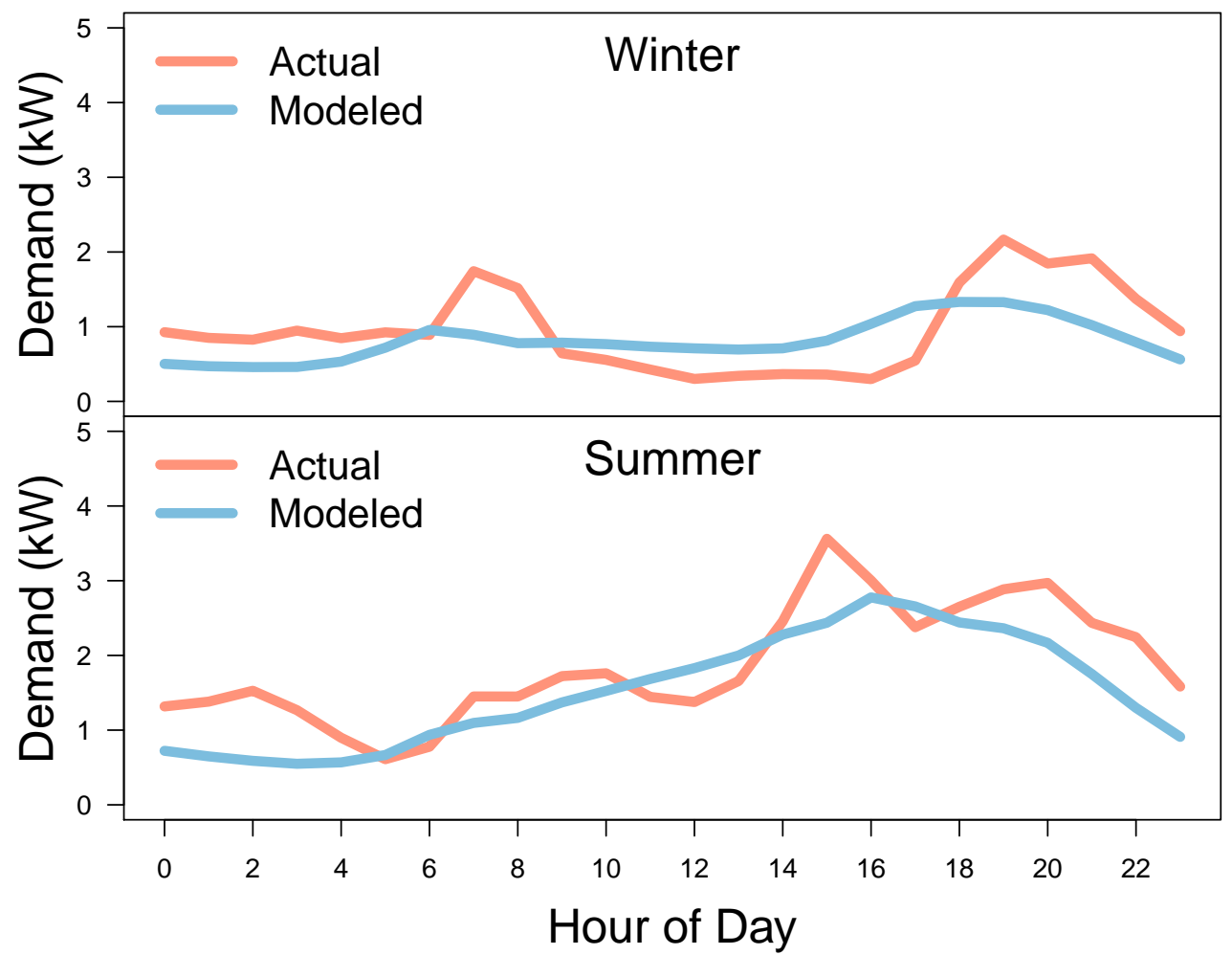

Figure 6: Temporal graph comparing hourly consumption patterns between simulation and measurement for an August day and a February day showing that the model is generally in good agreement with measured data most of the day in the summer time and slightly over predicts electricity consumption in the middle of the day in the winter but follows trends relatively well. Note that the data in this figure are only for 5 homes due to data availability. 

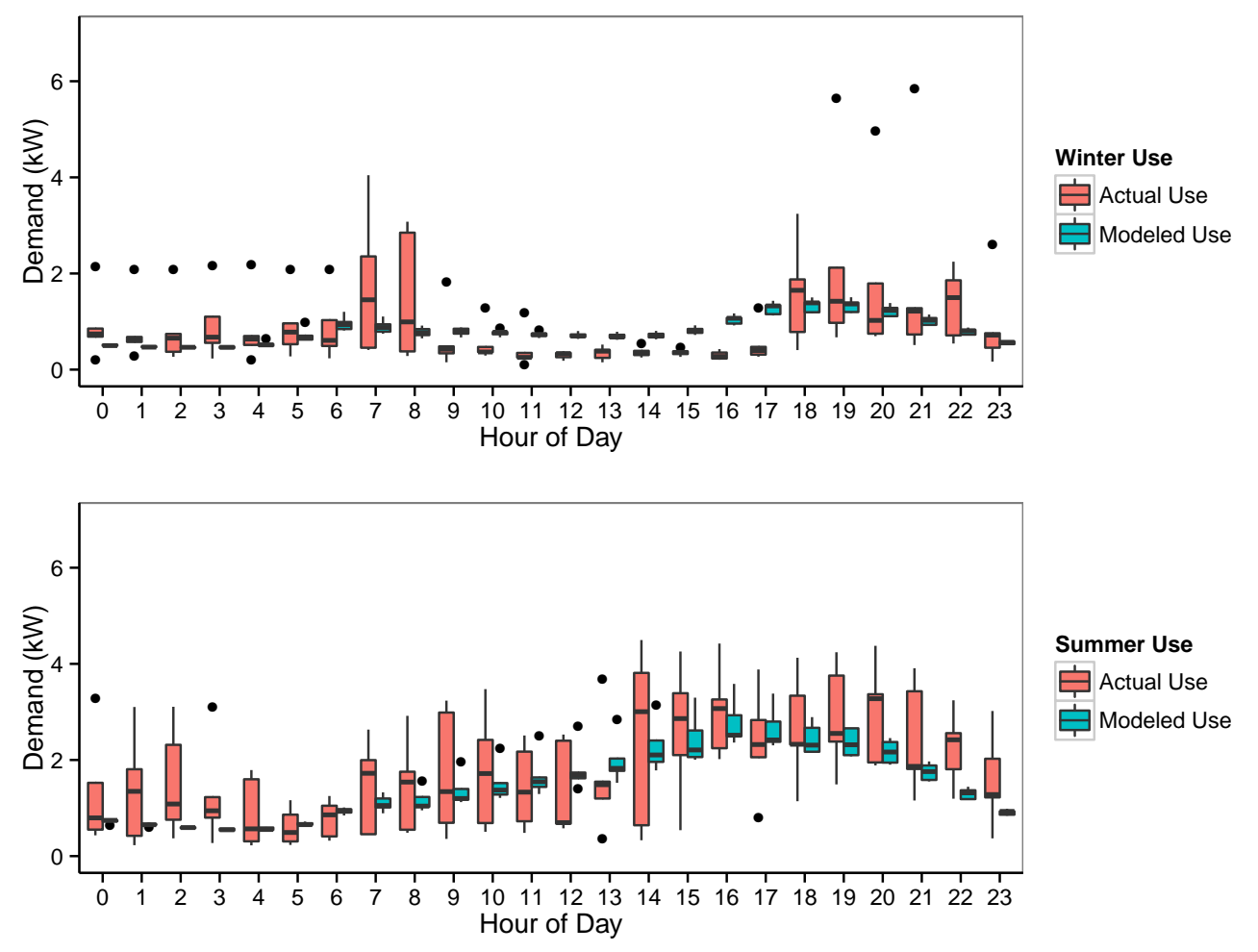

Figure 7: Temporal graph comparing hourly consumption patterns between simulation and measurement for an August day and a February day showing the variability of measured data as compared to modeled data. Note that the data for Figure 6 and Figure 7 are the same. 
geometries were changed from a complex geometry (B-I in Figure 3) to the A geometry type. Of the 32,13 of the homes were modified from a combination of complex two-storied construction to a two storied construction with different A geometry shapes placed on top of each other. Twelve of the models already were constructed with the A geometry shape and therefore were excluded from this analysis.

Overall, for the one-story changes, the homes only deviated by $1.31 \%$ on average from the original model values, and the two story changes only deviated by $1.07 \%$ on average from their original models. Furthermore, since square footage could not be maintained precisely when the simplified geometries were created, some of these differences could be explained simply by the change in area. On average, the one-storied models in scenario 4 changed by less than $5.1 \mathrm{ft}^{2}\left(0.47 \mathrm{~m}^{2}\right)$, and the two-storied models changed by $7.5 \mathrm{ft}^{2}$ $\left(0.7 \mathrm{~m}^{2}\right)$. Thus, results indicate that even without accurate geometry information for a real home, the model can produce plausible results. If the home was simplified to be more square than rectangular, the simplified geometry model deviated noticeably more from the original model than if the original model's square footage was only added to one side of the home, making a more rectangular shape and maintaing the surface area to volume ratio. See Figure 8 for a depiction of the suggested method to take (the one ultimately used by the authors) when simplifying a model to a rectangular shape.

When using the rule of thumb above, the simplified geometry models only deviated by $1.3 \%$ on average from the original models. However, when the homes were simplified to make a home more square, the simplified models deviated by $2.3 \%$ on average from the original models. This result might 


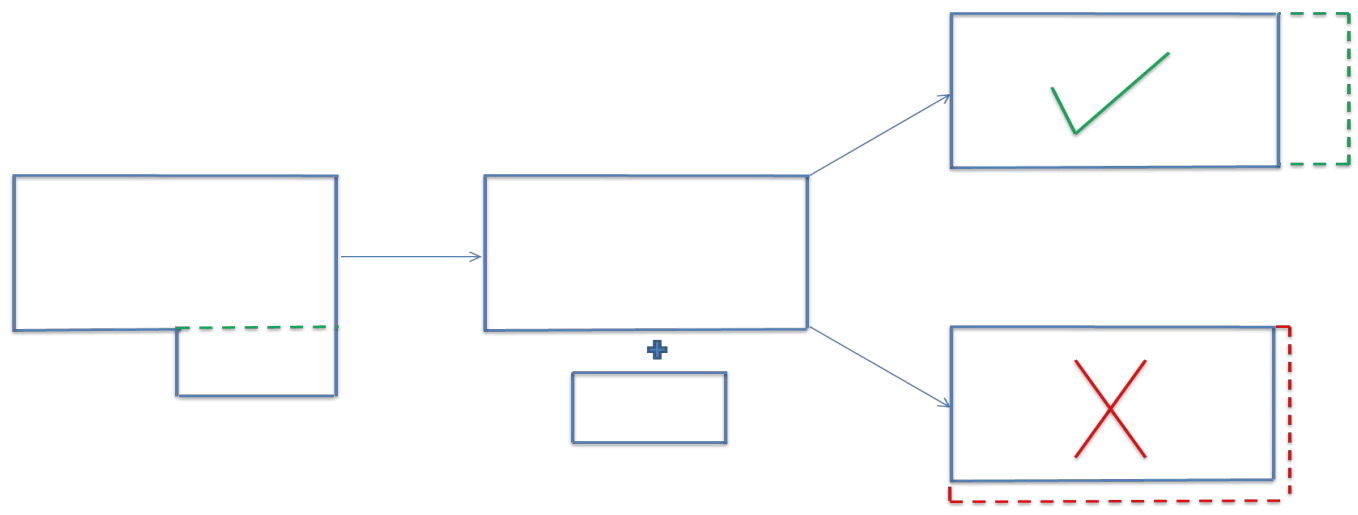

Figure 8: Example of a geometry simplification from type B to type A showing that, as suggested by this analysis, it is more appropriate to add floor space to one side of the home rather than on two sides.

become more important if home modeling is automated and extended to a large number of homes and complex home geometries need to be simplified for the automated process. Confirming that model output is not affected significantly should allow energy modelers to simplify their geometries or select geometries from a pre-defined list.

\section{Conclusions}

Given the integration and close comparison of two unique data sets including information about single-family homes and their hourly and yearly consumption data, we were able to quantify the accuracy of the BEopt simulation software under various conditions in Austin, TX. While model results for an individual home can have a wide range of error (up to 30\%), when considered in aggregate with actual weather data, the model performed much better (within 3\%). Furthermore, the analysis indicates that models of small 
homes or homes that have low values of energy consumed per square foot, do not perform as well, especially for homes well below the EIA average. Comparisons of temporal patterns of energy consumption showed that the model might be able to predict temporal energy use trends in the summer and winter times, though it has difficulty predicting exact values at specific times of the day. Finally, we determined that geometry adjustments do not significantly contribute (about 1\%) to a home's overall energy results, at least within the BEopt model framework. Thus, model building might be able to to streamlined for auto generation of energy models from energy audits.

\section{Acknowledgments}

The authors would like to thank the Doris Duke Charitable Foundation, the Department of Energy, Austin Energy, and Pecan Street Inc. for their direct and in-kind support. The authors would also like to thank the study participants and the Mueller neighborhood groups for their support.

\section{Disclosure of Affiliation}

In addition to research work on topics generally related to energy systems at the University of Texas at Austin, some of the authors are equity partners in IdeaSmiths LLC, which consults on topics in the same areas of interests. The terms of this arrangement have been reviewed and approved by the University of Texas at Austin in accordance with its policy on objectivity in research. 


\section{References}

\section{References}

[1] Energy Perspectives 1949-2010. Tech. Rep.; U.S. Energy Information Administration; 2010.

[2] Shammin, M.R.. Greenhouse Gases - Emission, Measurement and Management. InTech; 2012. URL: http://www.intechopen.com/books/ greenhouse-gases-emission-measurement-and-management.

[3] 2011 Buildings Energy Data Book. Report; US Department of Energy; 2011. URL: http://buildingsdatabook.eren.doe.gov/docs/ DataBooks/2011_BEDB.pdf.

[4] Residential Energy Consumption Survey (RECS) - Energy Information Administration. 2013. URL: http://www.eia.gov/consumption/ residential/.

[5] Doggett, T.. Overcoming Barriers to Smart Grids \& New Energy Services Electric Reliability Council of Texas. In: UT Smart Grid Conference. Austin; 2011,.

[6] Salamanca, F., Georgescu, M., Mahalov, A., Moustaoui, M., Wang, M.. Anthropogenic Heating of the Urban Environment due to Air Conditioning. Journal of Geophysical Research: Atmospheres 2014;:n/an/aURL: http://doi.wiley.com/10.1002/2013JD021225. doi:doi:10. 1002/2013JD021225. 
[7] Zhou, Y., Clarke, L., Eom, J., Kyle, P., Patel, P., Kim, S.H., et al. Modeling the effect of climate change on U.S. statelevel buildings energy demands in an integrated assessment framework. Applied Energy 2014;113:1077-1088. URL: http://linkinghub. elsevier.com/retrieve/pii/S0306261913006776. doi:doi:10.1016/j. apenergy.2013.08.034.

[8] Rhodes, J.D., Stephens, B., Webber, M.E.. Using energy audits to investigate the impacts of common air-conditioning design and installation issues on peak power demand and energy consumption in Austin, Texas. Energy and Buildings 2011;43(11):32713278. URL: http://www.sciencedirect.com/science/article/pii/ S0378778811003823, doi:doi:10.1016/j.enbuild.2011.08.032.

[9] Rhodes, J.D., Stephens, B., Webber, M.E.. Energy Audit Analysis of Residential Air-Conditioning Systems in Austin, Texas. ASHRAE Transactions 2012;118(1):143-150.

[10] Phillips, Y.. Landlords versus tenants: Information asymmetry and mismatched preferences for home energy efficiency. Energy Policy 2012;45:112-121. URL: http://linkinghub.elsevier. com/retrieve/pii/S030142151200095X. doi:doi:10.1016/j.enpol.2012. 01.067 .

[11] Sadineni, S.B., France, T.M., Boehm, R.F.. Economic feasibility of energy efficiency measures in residential buildings. Renewable Energy 2011;36(11):2925-2931. URL: http://linkinghub. 
elsevier.com/retrieve/pii/S0960148111001789. doi:doi:10.1016/j. renene.2011.04.006.

[12] Talavera, D., Muñoz Cerón, E., de la Casa, J., Ortega, M., Almonacid, G.. Energy and economic analysis for large-scale integration of small photovoltaic systems in buildings: The case of a public location in Southern Spain. Renewable and Sustainable Energy Reviews 2011;15(9):4310-4319. URL: http://linkinghub. elsevier.com/retrieve/pii/S1364032111003662, doi:doi:10.1016/j. rser.2011.07.119.

[13] Downey, T., Proctor, J.. What Can 13,000 Air Conditioners Tell Us? In: ACEEE Summer Study on Energy Efficiency in Building. Proctor Engineering Group, Ltd.; 2002,.

[14] Stephens, B., Siegel, J.a., Novoselac, A.. Operational characteristics of residential and light-commercial air-conditioning systems in a hot and humid climate zone. Building and Environment 2011;46(10):19721983. URL: http://linkinghub.elsevier.com/retrieve/pii/ S0360132311000989, doi:doi:10.1016/j.buildenv.2011.04.005.

[15] Stephens, B., Siegel, J.A., Novoselac, A.. Energy Implications of Filtration in Residential and Light-Commercial Buildings. ASHRAE Transactions 2010;116:346-357.

[16] Stephens, B., Novoselac, A., Siegel, J.. The Effects of Filtration on Pressure Drop and Energy Consumption in Residential HVAC Systems (RP-1299). HVAC\&R Research 2010;16(3):273-294. URL: http:// 
WWw. tandfonline.com/doi/abs/10.1080/10789669.2010.10390905

doi:doi:10.1080/10789669.2010.10390905.

[17] Erinjeri, J.J., Witriol, N.M., Katz, M.. Measurement of Return Leaks in Residential Buildings in North Louisiana. Journal of Building Physics 2009;32(3):261-280. URL: http://jen.sagepub.com/cgi/ doi/10.1177/1744259108093094. doi:doi:10.1177/1744259108093094.

[18] Hendron, R., Farrar-Nagy, S., Anderson, R., Reeves, P., Hancock, E.. Thermal Performance of Unvented Attics in Hot-Dry Climates: Results from Building America. Journal of Solar Energy Engineering 2004;126(2):732. URL: http://solarenergyengineering. asmedigitalcollection.asme. org/article. aspx?articleid=1456993, doi:doi:10.1115/1.1687795.

[19] Parker, D.S.. Research highlights from a large scale residential monitoring study in a hot climate. Energy and Buildings 2003;35(9):863876. URL: http://linkinghub.elsevier.com/retrieve/pii/ S037877880200244X. doi:doi:10.1016/S0378-7788(02)00244-X.

[20] Nemry, F., Uihlein, A., Colodel, C.M., Wetzel, C., Braune, A., Wittstock, B., et al. Options to reduce the environmental impacts of residential buildings in the European UnionPotential and costs. Energy and Buildings 2010;42(7):976-984. URL: http://linkinghub. elsevier.com/retrieve/pii/S0378778810000162. doi:doi:10.1016/j. enbuild.2010.01.009.

[21] Gustavsson, L., Joelsson, A.. Life cycle primary en- 
ergy analysis of residential buildings. Energy and Buildings 2010;42(2):210-220. URL: http://linkinghub.elsevier.com/ retrieve/pii/S0378778809002102. doi:doi:10.1016/j.enbuild.2009.08. 017.

[22] Neme, C., Proctor, J., Nadel, S.. Energy Savings Potential From Addressing Residential Air-conditioner and Heat Pump Installation Problems. Report A992; American Council for an Energy Efficient Economy; Washington, DC; 1999.

[23] Djuric, N., Novakovic, V.. Correlation between standards and the lifetime commissioning. Energy and Buildings 2010;42(4):510 521. URL: http://wwW.sciencedirect.com/science/article/pii/ S0378778809002588.

[24] Pan, W., Garmston, H.. Compliance with building energy regulations for new-build dwellings. Energy 2012;48(1):11-22. URL: http://www.sciencedirect.com/science/article/pii/ S0360544212004999http://linkinghub.elsevier.com/retrieve/ pii/S0360544212004999. doi:doi:10.1016/j.energy.2012.06.048.

[25] Vine, E.L.. Residential building code compliance: Implications for evaluating the performance of utility residential new construction programs. Energy 1996;21(12):1051-1058. URL: http://www.sciencedirect. com/science/article/pii/036054429600076X.

[26] Rutkowski, H.. Residential Load Calculation: Manual J. Arlington, VA: Air-conditioning Contractors of America; 2004. 
[27] 2009 ASHRAE Handbook - Fundamentals. 2009.

[28] Crawley, D.B., Hand, J.W., Kummert, M., Griffith, B.T.. Contrasting the capabilities of building energy performance simulation programs. Building and Environment 2008;43(4):661-673. URL: http: //linkinghub.elsevier.com/retrieve/pii/S0360132306003234. doi:doi:10.1016/j.buildenv.2006.10.027

[29] Polly, B., Kruis, N., Roberts, D.. Assessing and Improving the Accuracy of Energy Analysis for Residential Buildings. Tech. Rep.; National Renewable Energy Lab; Golden, CO; 2011. URL: http://apps1.eere.energy.gov/buildings/publications/pdfs/ building_america/energy_analysis_resbldgs.pdf.

[30] Christensen, C., Anderson, R., Horowitz, S., Courtney, A., Spencer, J.. BEopt Software for Building Energy Optimization : Features and Capabilities; 2006.

[31] Pigg, S., Nevius, M.. Energy and Housing in Wisconsin; 2000.

[32] Judkoff, R., Neymark, J.. Model Validation and Testing : The Methodological Foundation of ASHRAE Standard 140; 2006.

[33] Judkoff, R., Wortman, D., Doherty, B.O., Burch, J.. A Methodology for Validating Building Energy Analysis Simulations; 2008. URL: http://www.stanford.edu/group/narratives/classes/08-09/ CEE215/ReferenceLibrary/BIMandBuildingSimulationResearch/ AMethodologyforValidatingBuildingEnergyAnalysisSimulations . pdf. 
[34] Polly, B., Horowitz, S., Booten, C., Kruis, N., Nrel, C.C.. Automated Comparison of Building Energy Simulation Engines; 2012. URL: http: //www.nrel.gov/docs/fy12osti/52651.pdf.

[35] Hoque, S.. Building Simulation Tools for Retrofitting Residential Structures. Energy Engineering 2012;109(3):53-74. URL: http:// WWw.tandfonline.com/doi/abs/10.1080/01998595.2012.10491656. doi:doi:10.1080/01998595.2012.10491656.

[36] Schwartz, Y., Raslan, R.. Variations in results of building energy simulation tools, and their impact on BREEAM and LEED ratings: A case study. Energy and Buildings 2013;62:350-359. URL: http: //linkinghub.elsevier.com/retrieve/pii/S0378778813001904. doi:doi:10.1016/j.enbuild.2013.03.022.

[37] Nikolaou, T., Kolokotsa, D., Stavrakakis, G.. Review on methodologies for energy benchmarking, rating and classification of buildings. Advances in Building Energy Research 2011;5(1):53-70. URL: http://www.tandfonline.com/doi/abs/10. 1080/17512549.2011.582340, doi:doi:10.1080/17512549.2011.582340.

[38] Reilly, D., Duffy, A., Willis, D., Conlon, M.. Development and implementation of a simplified residential energy asset rating model. Energy and Buildings 2013;65:159-166. URL: http://linkinghub. elsevier.com/retrieve/pii/S0378778813002764. doi:doi:10.1016/j. enbuild.2013.04.023.

[39] Peng, C., Yan, D., Wu, R., Wang, C., Zhou, X., 
Jiang, Y.. Quantitative description and simulation of human behavior in residential buildings. Building Simulation 2011;5(2):8594. URL: http://link . springer.com/10.1007/s12273-011-0049-0. doi:doi:10.1007/s12273-011-0049-0.

[40] Ryan, E.M., Sanquist, T.F.. Validation of building energy modeling tools under idealized and realistic conditions. Energy and Buildings 2012;47:375-382. URL: http://linkinghub.elsevier.com/ retrieve/pii/S037877881100630X. doi:doi:10.1016/j.enbuild.2011.12. 020 .

[41] Chiou, Y.S., Carley, K.M., Davidson, C.I., Johnson, M.P.. A high spatial resolution residential energy model based on American Time Use Survey data and the bootstrap sampling method. Energy and Buildings 2011;43(12):3528-3538. URL: http://linkinghub. elsevier.com/retrieve/pii/S0378778811004087, doi:doi:10.1016/j. enbuild.2011.09.020.

[42] Ham, Y., Golparvar-Fard, M.. EPAR: Energy Performance Augmented Reality models for identification of building energy performance deviations between actual measurements and simulation results. Energy and Buildings 2013;63:15-28. URL: http://linkinghub.elsevier.com/ retrieve/pii/S0378778813001485, doi:doi:10.1016/j.enbuild.2013.02. 054 .

[43] Bianco, V., Rosa, M.D., Scarpa, F., Tagliafico, L.A.. Analysis of energy demand in residential buildings for different climates by means of dynamic simulation. Interna- 
tional Journal of Ambient Energy 2014;(April):1-33. URL: http://dx.doi.org/10.1080/01430750.2014.907207http: //www.tandfonline.com/doi/abs/10.1080/01430750.2014.907207. doi:doi:10.1080/01430750.2014.907207.

[44] Burgett, J.M., Chini, A.R., Oppenheim, P.. Specifying residential retrofit packages for $30 \%$ reductions in energy consumption in hothumid climate zones. Energy Efficiency 2013;6(3):523-543. URL: http://link.springer.com/10. 1007/s12053-012-9190-6. doi:doi:10.1007/s12053-012-9190-6.

[45] Rhodes, J.D., Upshaw, C.R., Harris, C.B., Meehan, C.M., Walling, D.A., Navrátil, P.A., et al. Experimental and data collection methods for a large-scale smart grid deployment: Methods and first results. Energy 2014;65:462-471. URL: http://linkinghub. elsevier.com/retrieve/pii/S0360544213009663, doi:doi:10.1016/j. energy.2013.11.004.

[46] Pecan Street's Mission \& Guiding Principles. 2014. URL: http://www. pecanstreet.org/about/mission-guiding-principles/.

[47] About the Energy Conservation Audit and Disclosure (ECAD) Ordinance. 2013. URL: http://www.austinenergy.com/aboutus/ environmentalinitiatives/ordinance/index.htm.

[48] Weather Source. 2013. URL: http://weathersource.com/.

[49] Austin Climate Summary. 2014. URL: http://www.srh.noaa.gov/ images/ewx/climate/ausclisum.pdf. 
${ }_{567}^{6}$ [50] Monthly Averages for Austin, TX. 2014. URL: http://www weather. 568 com/weather/wxclimatology/monthly/USTX0057.

${ }_{569}^{6}$ [51] DOE2.com Home Page. 2014. URL: http://www.doe2.com/

570 [52] Cole, W.J., Rhodes, J.D., Gorman, W., Perez, K.X., Webber, ${ }_{571}$ M.E., Edgar, T.F.. Community-scale residential air conditioning $572 \quad$ control for effective grid management. Applied Energy 2014;130:428-

573 4 436. URL: http://linkinghub.elsevier.com/retrieve/pii/ $574 \quad$ S0306261914005728, doi:doi:10.1016/j.apenergy.2014.05.067. 